\title{
Laboratory Study on Performance Evaluation and Automobile Exhaust Degradation of Nano-TiO 2 Particles-Modified Asphalt Materials
}

\author{
Yaozong Ma $\mathbb{D}^{1},{ }^{1,2}$ Lilin Li $\mathbb{D}^{3},{ }^{3}$ Hua Wang $\mathbb{D}^{3,}, 4$ Wensheng Wang $\mathbb{D}^{1},{ }^{1}$ and Kunkun Zheng $\mathbb{D}^{5}$ \\ ${ }^{1}$ College of Transportation, Jilin University, Changchun 130025, China \\ ${ }^{2}$ Guangxi Liyu Expressway Co. Ltd., Nanning 530005, China \\ ${ }^{3}$ Guangxi Transportation Science and Technology Group Co. Ltd., Nanning 530007, China \\ ${ }^{4}$ Guangxi Beibu Gulf Investment Group Co. Ltd., Nanning 530029, China \\ ${ }^{5}$ Guangdong Aohong Technology Co. Ltd., Zhongshan 528437, China
}

Correspondence should be addressed to Hua Wang; wanghua15@mails.jlu.edu.cn and Wensheng Wang; wangws@jlu.edu.cn

Received 9 January 2021; Revised 5 February 2021; Accepted 9 February 2021; Published 23 February 2021

Academic Editor: Qinglin Guo

Copyright (C) 2021 Yaozong Ma et al. This is an open access article distributed under the Creative Commons Attribution License, which permits unrestricted use, distribution, and reproduction in any medium, provided the original work is properly cited.

\begin{abstract}
Automobile exhaust pollution is a serious problem that restricts urban development, and it poses a serious threat to people's lives and health and even the climate. At present, the treatment of automobile exhaust has attracted people's attention, and numerous works have been focused on it thereafter. The purpose of the present study is to drive $\mathrm{TiO}_{2}$ nanoparticles application into pavement, and the study present an experimental investigation of performances and automobile exhaust purification of asphalt and its mixture modified by nano- $\mathrm{TiO}_{2}$. In this work, a series of rheometer properties and pavement performances were studied, including penetration, softening point, ductility, DSR and BBR for asphalt binder, conventional pavement performances, and creep test for asphalt mixture. Moreover, the photocatalytic degradation test of automobile exhaust was conducted to assess degradation of $\mathrm{TiO}_{2}$ nanoparticles in the asphalt mixture on automobile exhaust. Results indicate that the $\mathrm{TiO}_{2}$ nanoparticle was beneficial to increase the viscosity and reduce the temperature sensitivity, which would enhance its high-temperature stabilization capability of asphalt. Meanwhile, nano- $\mathrm{TiO}_{2}$ can significantly enhance the rheometer properties of asphalt and its capacity of hightemperature antirutting, and its low-temperature performance could also comply with the specification. Besides, the incorporation of nano- $\mathrm{TiO}_{2}$ in mixtures could effectively enhance the antirutting and anticracking as well as water stabilization. Moreover, the nano- $\mathrm{TiO}_{2}$-modified asphalt mixture possesses a positive impact on photocatalytic degradation of $\mathrm{CH}$ and $\mathrm{NO}_{\mathrm{x}}$, which could provide a reference for the treatment of automobile exhaust. The photocatalytic degradation effect of asphalt mixtures modified by nano- $\mathrm{TiO}_{2}$ on $\mathrm{NO}_{\mathrm{x}}$ is significantly better than that of $\mathrm{CH}$.
\end{abstract}

\section{Introduction}

With the global civilization process and the construction level development of road engineering, the functional requirements of roads are increasing, and the requirements for road service functions, green construction, and safety protection are more urgent [1-9]. With the rapid development of nanotechnology, more and more researchers are getting committed to introducing nanomaterials into the road pavement [10-12]. Nanomaterials refer to materials in the range of 1 100 nanometers in at least one dimension. It is worth noting that nanomaterials usually have the advantages of significant temperature susceptibility, better extendability, and larger specific surface area (SSA). Besides, the physical, chemical, and other properties of nanomaterials have great differences with the original raw materials [13]. Therefore, on the above basis, researchers introduced nanomaterials into road and construction fields.

Nowadays, the asphalt pavement has become the largest pavement type in China's high-level pavements [14-22]. However, it is worth noting that there are yet many problems in the field of flexible pavement that need to be solved 
urgently. The resulting damage will reduce the service performance of the asphalt flexible pavement, such as rutting, cracks, and other damage phenomena [15, 23-25]. A lot of related research work has been done, including modifying asphalt materials [26-28] and optimizing the asphalt flexible pavement structure [29]. Jahromi et al. employed two kinds of nanoclay to improve the performances of asphalt materials. According to X-ray diffraction along with DSR, nanoclay-modified asphalt increased stiffness and decreased the phase angle [30]. Abdelrahman et al. assessed the physical performances of asphalt through adding the modified nanoclay using dynamic mechanical analysis and showed that the incorporation of modified nanoclay materials into asphalt materials enhanced their physical properties. Also, they investigated the modification mechanism of nanoclay, which was considered to be the interactivity of the modified nanosilox tetrahedron in asphalt using the FTIR test [31]. You et al. used nanoclay to modify asphalt and compared two kinds of nanoclay. The results indicated that nanoclay could effectively boost the comprehensive performances of asphalt materials. Furthermore, the blending procedure was considered as the key to achieving a well-distributed nanoclay-modified asphalt [32]. Khattak et al. employed different dosages of carbon nanofibers to modify three types of asphalt cements based on two asphalt mixing procedures, i.e., dry and wet procedures. Due to the larger SSA, better interface combination effect, as well as higher modulus values of carbon nanofiber, the test results showed that carbon nanofiber-modified asphalt exhibited good viscoelastic response and fatigue performances [33].

On the contrary, the world has witnessed a rapid development of social urbanization, which has also resulted in increasing energy consumption and car ownership, bringing about many environmental problems $[34,35]$. Among them, atmospheric pollution and the decline of air quality have a huge negative effect on people's health and the ecology of the Earth, such as smoggy weather and respiratory diseases $[36,37]$. Currently, catalytic materials are widely used for automobile exhaust gas cleaning, which are mostly semiconductor materials and have their own catalytic function [38]. Semiconductor catalytic materials (such as $\mathrm{Fe}_{2} \mathrm{O}_{3}, \mathrm{ZnO}$, $\mathrm{TiO}_{2}$, and $\mathrm{CdS}$ ) can be used to a greater extent to generate free electrons and holes from visible solar light sources, of which $\mathrm{TiO}_{2}$ is the most widely used catalytic material, with good stability, catalytic properties, and low prices [39-41]. Chen et al. utilized nano- $\mathrm{TiO}_{2}$ to modify asphalt through permeability technology and evaluated the penetration effect using the scanning electron microscope. Because of the large surface area and advanced oxidation technology of nano$\mathrm{TiO}_{2}$, nano- $\mathrm{TiO}_{2}$-modified asphalt produced good performances of asphalt and also had a good environment purification function [42]. Hashimoto et al. applied $\mathrm{TiO}_{2}$ to a highway to achieve photocatalytic vehicle exhaust [43]. Loftness et al. studied the effect of photocatalytic automobile exhaust by applying $\mathrm{TiO}_{2}$ as a coating to the test road [44]. Jin et al. prepared composite nanomaterials by adding anatase-type nano- $\mathrm{TiO}_{2}$ to montmorillonite, which significantly reduced the agglomeration problem of $\mathrm{TiO}_{2}$ and studied the road performance and photocatalytic degradation of automobile exhaust when containing the composite nanomaterial [45]. Qian et al. tested aging for SBS asphalt containing nano- $\mathrm{TiO}_{2}$. In addition, a photocatalytic reaction system was developed to study the photocatalytic degradation analysis of nano- $\mathrm{TiO}_{2}$ on $\mathrm{NO}_{\mathrm{x}}$ [46]

Through the abovementioned literature analysis, it can be found that nanomaterials have been widely utilized in pavement engineering. But the research of nano- $\mathrm{TiO}_{2}$ in flexible roads is yet not systematic, and its application still needs to be improved. Therefore, this research designs for nano- $\mathrm{TiO}_{2}$ nanoparticles applied in asphalt road. The impacts of nano- $\mathrm{TiO}_{2}$ are evaluated mainly based on several indexes of conventional tests, and its rheological properties are evaluated through DSR and BBR. In addition, the influences of nano- $\mathrm{TiO}_{2}$ on asphalt road and creep characteristics of mixtures were also studied. Finally, the automobile exhaust purification is performed by simulating the actual environment to assess the degradation of nano$\mathrm{TiO}_{2}$ in the asphalt mixture on automobile exhaust.

\section{Materials and Methods}

\subsection{Materials and Samples}

\subsubsection{Materials}

(1) Asphalt. AH-90 was used, obtained from Panjin Petroleum Asphalt Co., Ltd. Table 1 presents the main technical indicators.

(2) $\mathrm{Nano}-\mathrm{TiO}_{2}$. The nanomaterial used in this paper is titanium dioxide, anatase crystal structure with the formula of $\mathrm{TiO}_{2}$. Its detailed technical characteristics are presented in Table 2.

(3) Coarse and Fine Aggregates and Mineral Powder. In this paper, stones are acquired from the local area, and the powder in the asphalt mixture is the limestone powder from Antu, Jilin Province. Referring to the requirements of JTG F40-2004, Tables 3-5 show the main technical properties of aggregates and limestone powder.

2.1.2. Sample Preparation Procedure. According to previous studies, it has been noted that the reasonable dosage of nano$\mathrm{TiO}_{2}$ is $5 \%$ in weight of asphalt [47]. During the preparatory stage of nano- $\mathrm{TiO}_{2}$-modified asphalt, original asphalt materials were preheated to $160^{\circ} \mathrm{C}$, and next, they were blended with weighted nano- $\mathrm{TiO}_{2}$ by manually stirring for $5 \sim 8 \mathrm{~min}$. The corresponding temperature increased to $170^{\circ} \mathrm{C}$ in a short time. Finally, apply the high-speed shearing at $6000 \mathrm{r} / \mathrm{min}$ and $170^{\circ} \mathrm{C}$ for $(40 \pm 5) \mathrm{min}$. When used, heat the asphalt sample again to $170^{\circ} \mathrm{C}$, control the shearing speed at 450 600 r/min, and stir continuously for about $20 \mathrm{~min}$.

As for the preparation of the AC mixture, CAVF is selected to design asphalt mixture gradation including base asphalt and nano- $\mathrm{TiO}_{2}$-modified asphalt, as shown in Figure 1 [48]. Following the JTG E20-2011 specification, the optimum asphaltaggregate ratios of the base original asphalt mixture as well as the nano- $\mathrm{TiO}_{2}$-modified asphalt mixture were obtained by the Marshall design method. Marshall stability, flow, air voids, etc., 
TABLE 1: Technical indicators of AH-90.

\begin{tabular}{lc}
\hline Technical indicators & Tested \\
\hline Penetration & 88.9 \\
Ductility & $>100$ \\
Softening point & 43.2 \\
Density & 1.017 \\
Dynamic viscosity & 0.295 \\
\hline RTFOT & \\
Weight loss & -0.191 \\
Residual penetration ratio & 84.9 \\
\hline
\end{tabular}

TABle 2: Technical indicators of nano- $\mathrm{TiO}_{2}$.

\begin{tabular}{llc}
\hline \multicolumn{1}{c}{ Technical indicators } & & Values \\
\hline Appearance & - & White powder \\
Structure & - & Anatase \\
Diameter & $\mathrm{nm}$ & 25 \\
Density & $\mathrm{g} / \mathrm{cm}^{3}$ & 3.8 \\
Specific surface area & $\mathrm{m}^{2} / \mathrm{g}$ & 60 \\
Purity & $\%$ & 99.5 \\
\hline
\end{tabular}

TABle 3: Technical indicators of coarse aggregate in this paper.

\begin{tabular}{lccc}
\hline \multicolumn{1}{c}{ Technical indicators } & Units & Values \\
\hline Los Angeles abrasion value & & $\%$ & 16.9 \\
Crushing value & $\%$ & 13.3 \\
& $13.2 \mathrm{~mm}$ & & 2.827 \\
Apparent specific gravity & $9.5 \mathrm{~mm}$ & - & 2.802 \\
& $4.75 \mathrm{~mm}$ & & 2.845 \\
& $13.2 \mathrm{~mm}$ & & 0.64 \\
Water absorption & $9.5 \mathrm{~mm}$ & $\%$ & 0.37 \\
& $4.75 \mathrm{~mm}$ & & 0.89 \\
Flat and elongated particle content & $\%$ & 8.7 \\
\hline
\end{tabular}

TABLE 4: Technical properties of fine aggregate in this paper.

\begin{tabular}{lcc}
\hline Technical properties & Units & Values \\
\hline Apparent specific gravity & - & 2.762 \\
Sand equivalent & $\%$ & 76 \\
\hline
\end{tabular}

TABLE 5: Technical properties of the mineral powder in this paper.

\begin{tabular}{|c|c|c|c|}
\hline \multicolumn{2}{|c|}{ Technical properties } & \multirow{2}{*}{$\frac{\text { Units }}{\mathrm{kg} / \mathrm{m}^{3}}$} & \multirow{2}{*}{$\frac{\text { Values }}{2.746 \times 10^{-3}}$} \\
\hline Apparent density & & & \\
\hline Hydrophilic coefficient & & - & 0.88 \\
\hline Water content & & $\%$ & 0.88 \\
\hline Plastic index & & $\%$ & 2 \\
\hline \multirow{3}{*}{ Granular composition } & $<0.6 \mathrm{~mm}$ & & 100 \\
\hline & $<0.15 \mathrm{~mm}$ & $\%$ & 98.5 \\
\hline & $<0.075 \mathrm{~mm}$ & & 78.6 \\
\hline
\end{tabular}

have been comprehensively considered $[29,49]$. The detailed preparation procedure of nano- $\mathrm{TiO}_{2}$-modified asphalt and mixture is shown in Figure 2.

\subsection{Laboratory Experiments}

\subsubsection{Conventional Tests and Rheometer Tests of Asphalt}

(1) Conventional Tests. The penetration test has been performed to analyze consistency of asphalt, which is carried out at $25^{\circ} \mathrm{C}$ following JTG E20-2011 T 0604. The softening point (SP) test is adopted for asphalt materials, which is determined by a ring and ball apparatus following the JTG E20-2011 T 0606 (ASTM D36) specification. The ductility property of asphalt materials is measured by the ductility test following the JTG E20-2011 T 0605 specification. The asphalt samples with standard size are stretched until broken. Then, the ductility value is defined as the stretched distance at breaking.

(2) Dynamic Shear Rheometer Test. DSR developed by SHRP has been employed for dynamic characteristics and evaluating the viscoelastic behavior of asphalt materials [50-52]. Compared to static experiments (penetration and softening point), the DSR test has more intuitive and real advantages to assess the properties of asphalt materials. According to the ASTM D7175 (AASHTO T31509) specification, the rheological parameters of asphalt materials are determined. By using two parallel plates at this temperature, the DSR test is carried out under temperature and frequency sweep modes, respectively.

In the DSR test, the dynamic viscoelastic characteristics of asphalt can be divided into two parts. $G^{*}$ is generally calculated by applying dynamic shear stress $\left(\tau_{\max }\right)$ to the asphalt sample and the corresponding measured shear strain $\left(\gamma_{\max }\right)$, defined in equation (1). The characteristics $(\delta)$ reflect the ratio of viscoelasticity in asphalt. When at higher temperature or lower frequency loading, asphalt is more prone to the viscous flow, so the phase angle is larger. While, at lower temperature or higher frequency loading, asphalt exhibits more elastic properties, and the phase angle is smaller.

$$
G^{*}=\frac{\tau_{\max }}{\gamma_{\max }} .
$$

(3) Beam Bending Rheometer Test. BBR was used to measure hardness of the asphalt beam with a dimension of $6.25 \times 12.5 \times 127 \mathrm{~mm}$ under creep loading based on the theory of engineering beam [51]. In the BBR test, according to the ASTM D6648 specification, the small asphalt binder beam is prepared and kept in the bath. Then, the asphalt binder beam is tested at $-18^{\circ} \mathrm{C}$. A load of $100 \mathrm{~g}$ is imposed to the asphalt beam, and the corresponding deformations are obtained. Therefore, two parameters can be obtained from the deflection curves versus time, i.e., $S(t)$ and $m$ value. Their equations are expressed as follows:

$$
\begin{aligned}
S(t) & =\frac{P l^{3}}{4 b h^{3} u(t)}, \\
\log S(t) & =A+B \lg t+C(\lg t)^{2}, \\
m(t) & =|B+2 C \lg t|,
\end{aligned}
$$




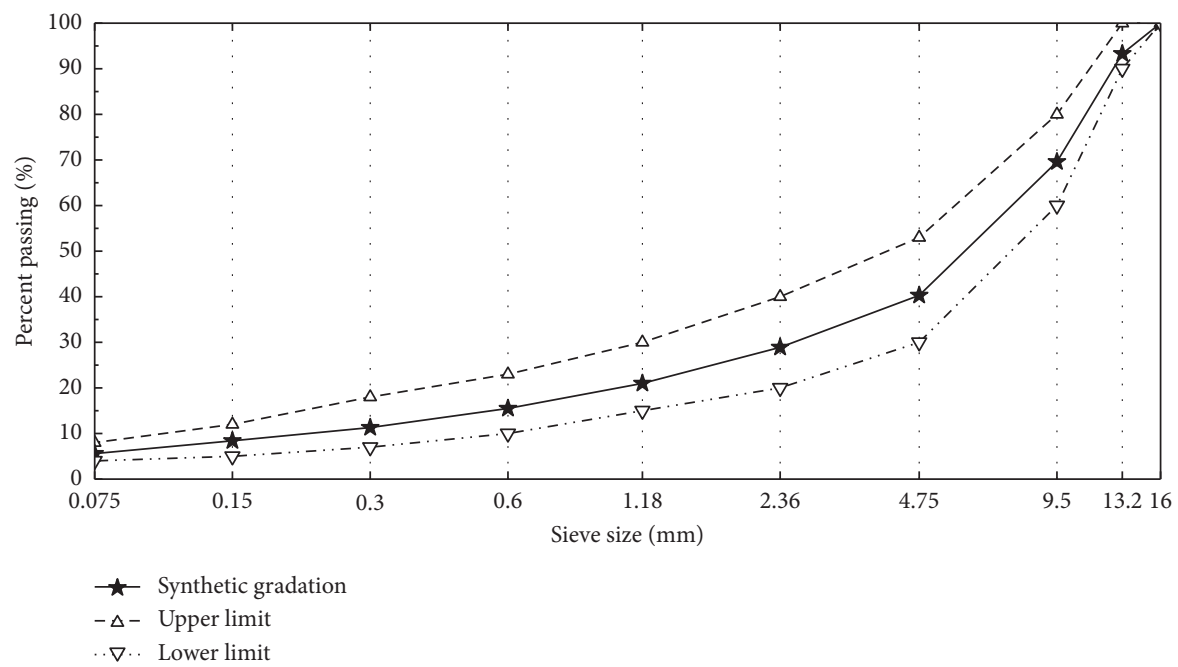

Figure 1: Asphalt mixture gradation curve in this paper.
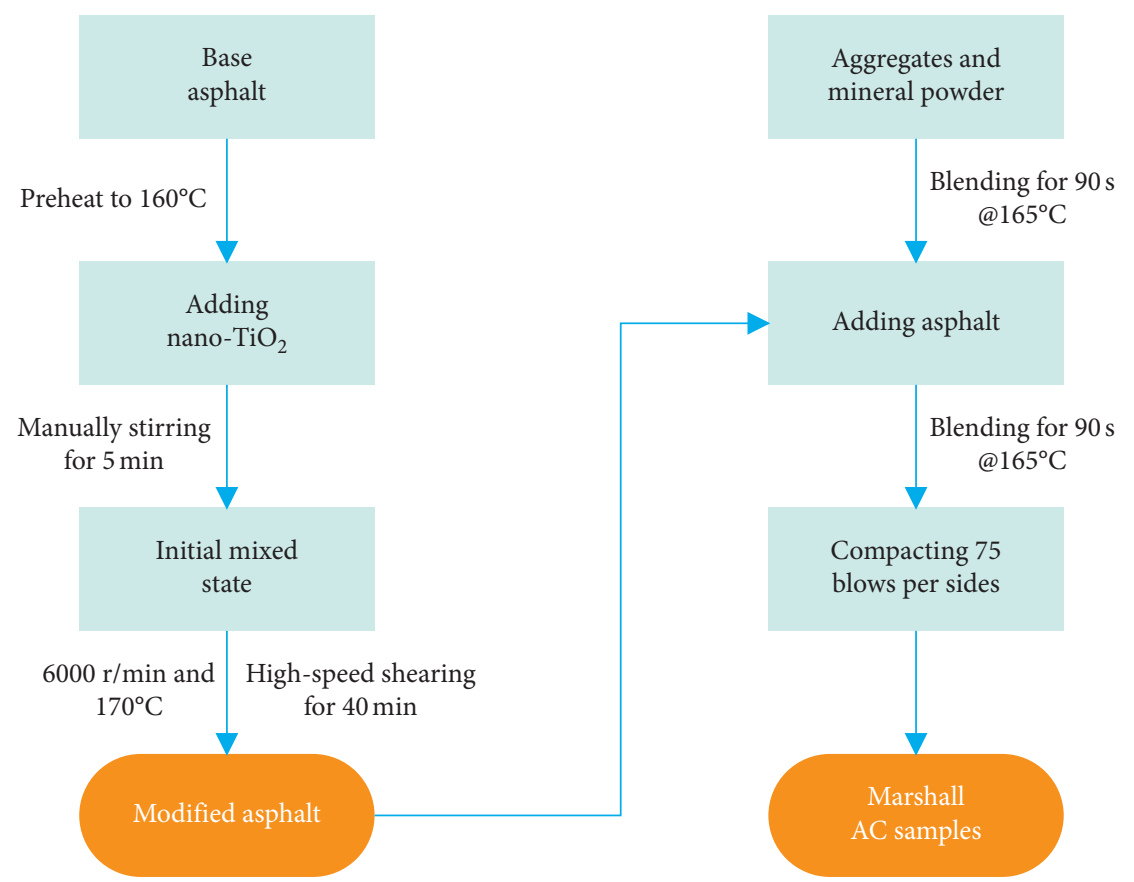

FIGURE 2: Sample preparation steps.

in which $P$ represents an imposed force, $l, b$, and $h$ are the beam dimensions, and $A, B$, and $C$ are empirically determined constants.

\subsubsection{Pavement Performances and Viscoelastic Properties Tests of the Asphalt Mixture}

(1) Pavement Performance Tests. This paper investigated and assessed the pavement performances of the asphalt mixture by using rutting test, flexural experiment, and freeze-thaw (F-T) splitting. Referring to JTG E20-2011 T 0719, firstly, square slab samples of asphalt mixtures $(300 \times 300 \times 50 \mathrm{~mm})$ were prepared, and perform the high-temperature rutting test at a rolling speed $N=(42 \pm 1)$ cycles $/ \mathrm{min}$. Then, the hightemperature performance could be evaluated by the index of dynamic stability (DS), which is calculated through the deflections $d_{45}$ and $d_{60}$ :

$$
\text { DS }=\frac{15 \times N}{d_{60}-d_{45}}
$$

The flexural experiment is conducted to assess the lowtemperature mechanical performance of the asphalt mixture. Referring to JTG E20-2011 T 0715, the prism samples $(250 \times 30 \times 35 \mathrm{~mm})$ were loaded by a pressure. Through the obtained deflection as well as load, $R_{B}$ and $\varepsilon_{B}$ 
as well as $S_{B}$ could be calculated according to the following:

$$
\begin{aligned}
& R_{B}=\frac{3 \times L \times P_{B}}{2 \times b \times h^{2}}, \\
& \varepsilon_{B}=\frac{6 \times h \times d}{L^{2}}, \\
& S_{B}=\frac{R_{B}}{\varepsilon_{B}} .
\end{aligned}
$$

Referring to JTG E20-2011 T 0729, F-T splitting was selected to analyze water sensitivity. Marshall specimens were prepared by one freeze-thaw cycle and without the freeze-thaw cycle, respectively. Then, these specimens were loaded. Through obtained results $\left(R_{T 1}\right.$ for the Marshall specimen without the freeze-thaw cycle and $R_{T 2}$ for the Marshall specimen under one cycle), TSR is defined as follows:

$$
\mathrm{TSR}=\frac{R_{T 2}}{R_{T 1}} \times 100 .
$$

(2) Uniaxial Static Compression Creep Test. The creep test methods mainly include uniaxial static compression creep, bending creep and splitting creep, and dynamic triaxial compression creep. At present, the commonly used creep test methods in the world for the asphalt mixture are mainly uniaxial static compression creep and bending creep. A major advantage of the uniaxial static compression creep test is that the test equipment is relatively simple; therefore, this creep test method has been widely used [53, 54].

The experiment has been performed for base original asphalt mixture and nano- $\mathrm{TiO}_{2}$-modified asphalt mixture specimens using a NU-14 tester, whose sensor measurement accuracy is $0.001 \%$. Before the test, a smooth polytetrafluoroethylene (PTFE) plastic film was placed on the upper and lower surfaces of the asphalt mixture sample to eliminate or reduce the influence of friction on contact surfaces. Meanwhile, asphalt mixture samples should be kept to make inside samples uniform. During the uniaxial static compression creep test, both sides of test samples are required to be flat to prevent local stress concentration from affecting the deformation response. At the beginning of the creep test, a loading of $0.002 \mathrm{MPa}$ was preloaded first, and then, the loading for $2700 \mathrm{~s}$ as well as unloading for $1800 \mathrm{~s}$ were carried out. During the creep test, the deformation data of samples were collected by linear variable differential transformer (LVDT) sensors.

2.2.3. Photocatalytic Degradation Test. Photocatalytic degradation test was conducted by the MQW-50A exhaust gas analyzer, as illustrated in Figure 3 . The square slab sample $(300 \times 300 \times 50 \mathrm{~mm})$ was also used and placed at the bottom of the reaction box. Then, the position of the ultraviolet lamp was adjusted at $135 \mathrm{~mm}$ from the test slab sample [41]. The automobile exhaust pipe was regarded as the exhaust supply, which was connected with the air inlet of the reaction box.
Cover the reaction box with a light-shielding cloth, turn on the ultraviolet light, and monitor the contents of $\mathrm{CH}$ and $\mathrm{NO}_{\mathrm{x}}$ in real time through the automobile exhaust gas analyzer. The photocatalytic degradation test of automobile exhaust would last $60 \mathrm{~min}$, and the contents of $\mathrm{CH}$ and $\mathrm{NO}_{\mathrm{x}}$ were checked every $10 \mathrm{~min}$. The photocatalytic degradation rate $(\mathrm{PDR})$ and concentration variation $(\mathrm{CV})$ of automobile exhaust can be calculated as follows:

$$
\begin{aligned}
\mathrm{PDR}_{i} & =\frac{\mathrm{Gas}_{i-1}-\mathrm{Gas}_{i}}{\text { Duration }} \times 100, \\
\mathrm{CV} & =\frac{\mathrm{Gas}_{0}-\mathrm{Gas}_{i}}{\mathrm{Gas}_{0}}
\end{aligned}
$$

where $\mathrm{Gas}_{i-1}$ and $\mathrm{Gas}_{i}$ are the initial and tested concentration of automobile exhaust (i.e., $\mathrm{CH}$ and $\mathrm{NO}_{\mathrm{x}}$ ) for each duration $(i=1,2,3,4,5,6)$, respectively. Duration is the reaction time between two photocatalytic degradation tests, and duration $=10 \mathrm{~min}$. $\mathrm{Gas}_{0}$ is the initial concentration of automobile exhaust (i.e., $\mathrm{CH}$ and $\mathrm{NO}_{\mathrm{x}}$ ).

\section{Results and Discussion}

\subsection{Analysis of Conventional and Rheometer Properties of Asphalt}

3.1.1. Conventional Tests Analysis. The experimental results of conventional physical performances of asphalt with and without nano- $\mathrm{TiO}_{2}$ are plotted in Figure 4. It is observed that the penetration at $25^{\circ} \mathrm{C}$ containing nano- $\mathrm{TiO}_{2}$ decreases significantly compared with base asphalt, which shows that adding nano- $\mathrm{TiO}_{2}$ reduced the sensitivity of asphalt to temperature. Besides, the softening point increases slightly through the addition of nano- $\mathrm{TiO}_{2}$. It shows that the stabilization capability of asphalt could be enhanced by nano$\mathrm{TiO}_{2}$. On the contrary, the ductility at $10^{\circ} \mathrm{C}$ of both base asphalt and nano- $\mathrm{TiO}_{2}$-modified asphalt are higher than $100 \mathrm{~cm}$, which could conform to JTG F40-2004. The above changing trend indicates that adding $5 \%$ nano- $\mathrm{TiO}_{2}$ would decrease the sensitivity of asphalt to temperature and increase its high-temperature properties.

\subsubsection{Dynamic Shear Rheometer Test Analysis}

(1) Temperature Sweep Test. Asphalt has significant temperature sensitivity and has different mechanical properties at different temperatures. To explore the rheological characteristics of the asphalt binder in medium- and hightemperature ranges, the DSR test was conducted at $10 \mathrm{rad} / \mathrm{s}$ from $40^{\circ} \mathrm{C}$ to $80^{\circ} \mathrm{C}$, and the strain controlled at $12 \%$. The measured $G^{*}$ and $\delta$ results versus temperature are plotted in Figure 5 .

$G^{*}$ values decrease with the increasing of test temperature in Figure 5(a). This is because the fluidity of asphalt increases as the temperature increases, and it is prone to emerge in more significant deformation at the same stress level. Clearly, a higher complex shear modulus is generally required to ensure that the asphalt pavement still has a good resistance to 


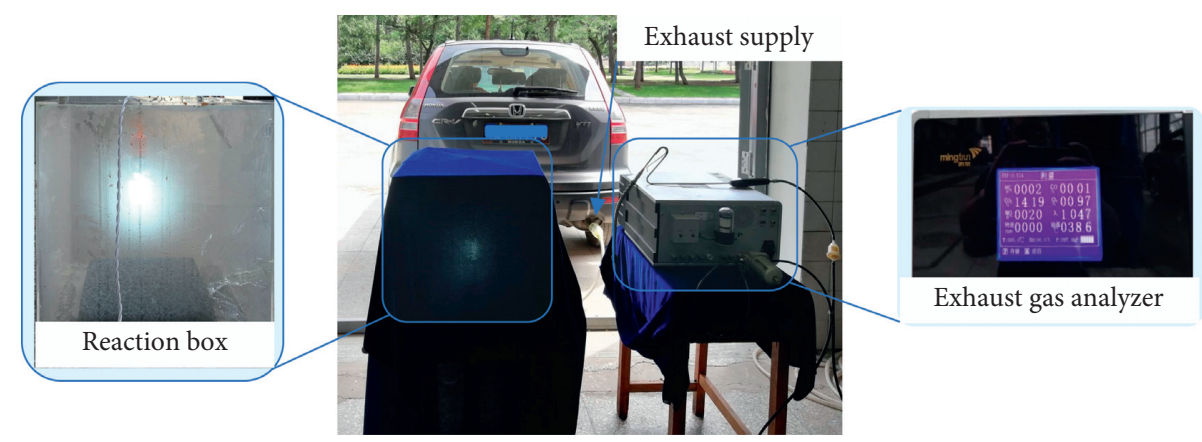

FIgURE 3: The photocatalytic degradation test.

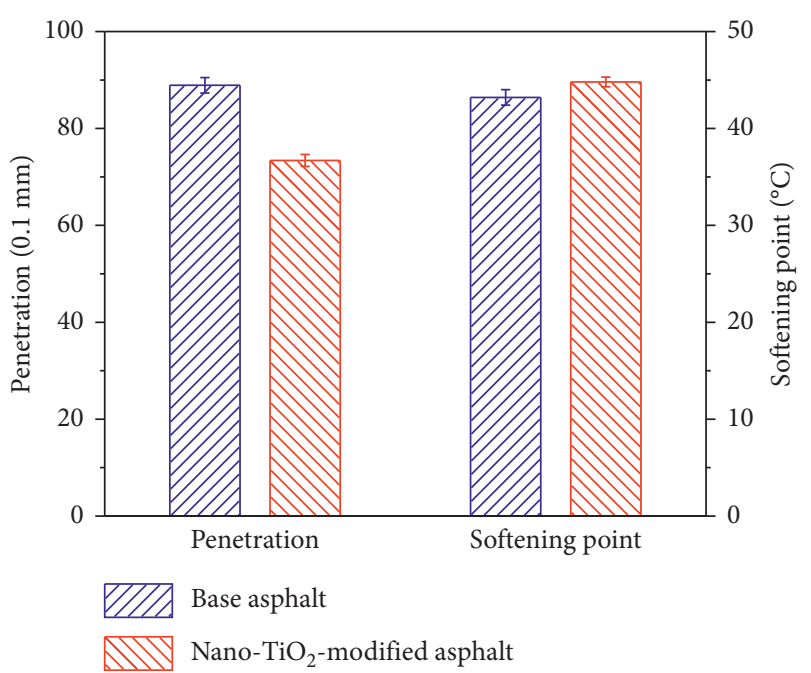

Figure 4: Penetration and softening point results of asphalt samples with and without nano- $\mathrm{TiO}_{2}$.

high-temperature deformation. Furthermore, while by comparison, the increase of $G^{*}$ value of nano- $\mathrm{TiO}_{2}$-modified asphalt is lower at $40^{\circ} \mathrm{C}$, and the corresponding increase in value is much higher at $80^{\circ} \mathrm{C}$. This indicates that the asphalt modified by nano- $\mathrm{TiO}_{2}$ has a higher temperature stability than original asphalt due to the higher complex shear modulus.

The characteristics $(\delta)$ is the relative indicatrix between recoverable and unrecoverable deformation, in which $\delta=0^{\circ}$ for elastic solids and $\delta=90^{\circ}$ for viscous fluids. In Figure 5(b), $\delta$ values increase as test temperature increases, which fully reflects the characteristics of a viscous fluid for asphalt as a typical viscoelastic material. With test temperature varying in the range of $40 \sim 80^{\circ} \mathrm{C}, \delta$ values of base asphalt change about $27^{\circ}$, and $\delta$ values of the modified one change about $26^{\circ}$. This implies that asphalt modified by nano- $\mathrm{TiO}_{2}$ has a lower temperature sensitivity. Moreover, since the flow deformation of nano- $\mathrm{TiO}_{2}$-modified asphalt at high temperature is smaller, nano- $\mathrm{TiO}_{2}$ is beneficial for the asphalt pavement to resist high-temperature deformation.

However, it generally needs to use different indicators to evaluate the performances of asphalt for various performances at different test conditions by $G^{*}$ and $\delta$ values. Many studies have shown that $G^{*} / \sin \delta$ represents the rutting factor
[55]. The larger the value of $G^{*} / \sin \delta$, the better the ability to resist deformation. Therefore, compared to static tests (such as penetration and softening point), dynamic tests have more intuitive and real advantages to evaluate the performances of asphalt binders. In general, the high-temperature range of the asphalt pavement is generally taken as $40^{\circ} \mathrm{C} \sim$ $80^{\circ} \mathrm{C}$, and the rutting factor results of base and modified asphalt by nano- $\mathrm{TiO}_{2}$ are plotted in Figure 6. As seen, the rutting factor of nano- $\mathrm{TiO}_{2}$-modified asphalt is larger by comparison at the same test temperature, which means asphalt modified by nano- $\mathrm{TiO}_{2}$ has a better high-temperature antirutting ability. Moreover, the growth rate of the rutting factor for nano- $\mathrm{TiO}_{2}$-modified asphalt changes from $5 \%$ to $13 \%$ when the test temperature increases from $40^{\circ} \mathrm{C}$ to $80^{\circ} \mathrm{C}$. This also implies that asphalt modified by nano- $\mathrm{TiO}_{2}$ possesses a good rutting resistance.

(2) Frequency Sweep Test. The frequency sweep test is currently the most popular method for investigating viscoelastic mechanical parameters of asphalt. The dynamic shear modulus mechanical response of asphalt in the linear viscoelastic range can be obtained using the DSR test with the small-strain level under different loading frequencies at the test temperature. To explore the viscoelastic properties of nano- $\mathrm{TiO}_{2}$-modified asphalt at higher temperature, the frequency sweep experiment was conducted based on the DSR test from 40 to $80^{\circ} \mathrm{C}$ with an interval temperature of $10^{\circ} \mathrm{C}$ for base and modified asphalt by nano- $\mathrm{TiO}_{2}$. Before the frequency sweep test, asphalt needs to be kept at test temperature for at least $15 \mathrm{~min}$. Figure 7 illustrates the measured $G^{*}$ varying with frequency.

As loading frequency rises, complex shear modulus of both base asphalt and nano- $\mathrm{TiO}_{2}$-modified asphalt increases and shows a linear growth trend in the logarithmic coordinate. Simultaneously, from the perspective of slope, modified asphalt possesses a high growth speed, meaning nano- $\mathrm{TiO}_{2}$-modified asphalt has a larger complex shear modulus than base asphalt.

3.1.3. Beam-Bending Rheometer Test Analysis. The creep deformations versus loading time at $-18^{\circ} \mathrm{C}$ have been measured, and the deflection-time curve reflects the typical viscoelastic behavior of asphalt. Although the creep characteristics of base asphalt and nano- $\mathrm{TiO}_{2}$-modified asphalt are not essentially different, their proportion of viscoelastic 


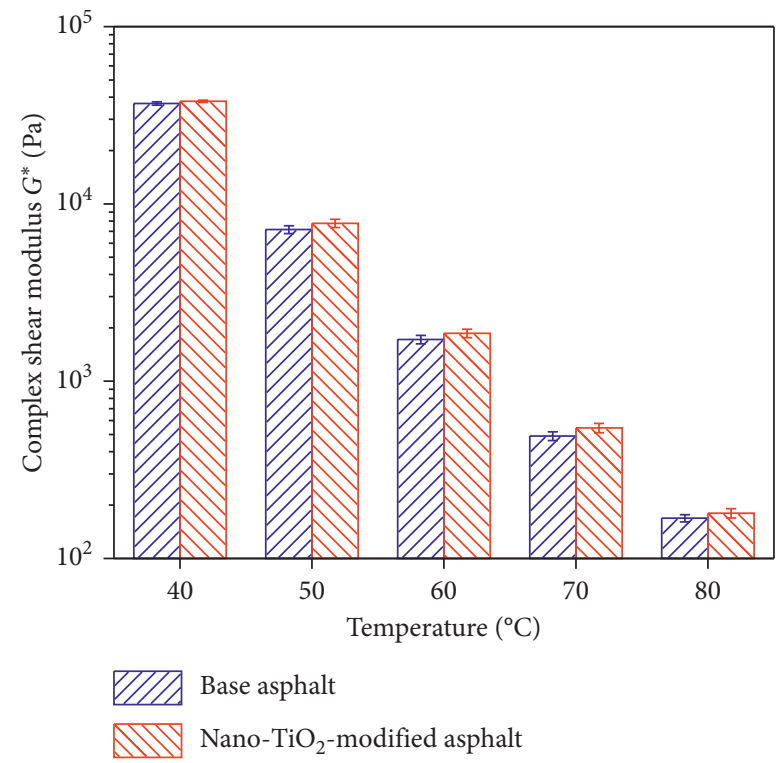

(a)

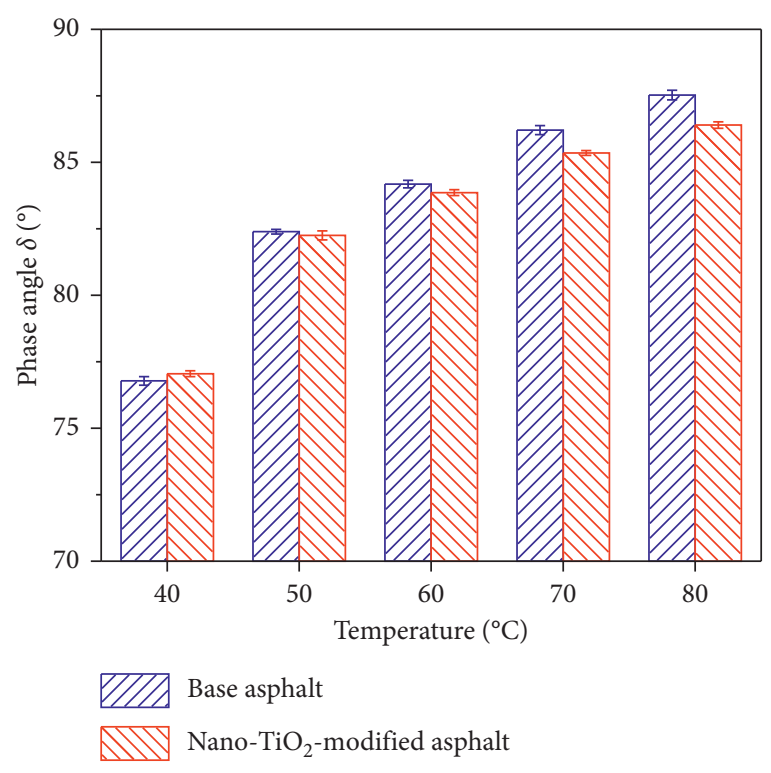

(b)

Figure 5: Temperature sweep test of asphalt with and without nano- $\mathrm{TiO}_{2}$. (a) $G *$. (b) $\delta$.

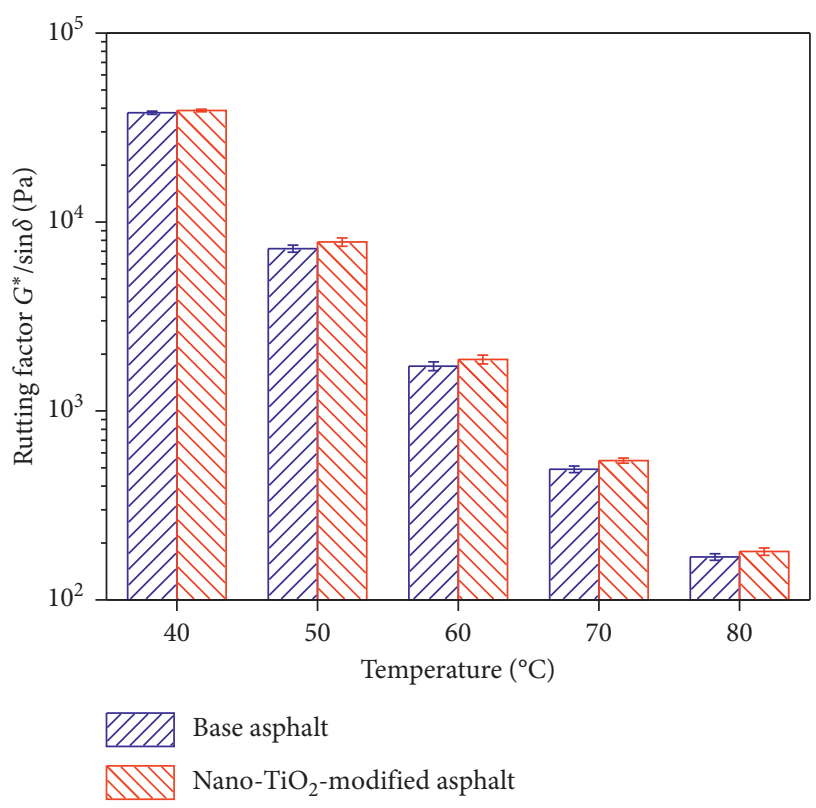

FIgURE 6: $G * / \sin \delta$ comparison results.

components have been changed. Under the same constant load, the deformation of nano- $\mathrm{TiO}_{2}$-modified asphalt is smaller by comparison, which means that incorporating nano- $\mathrm{TiO}_{2}$ improves the elastic component of asphalt, but decreases the viscosity component.

In the specifications of SHRP, the stiffness modulus result and its changing $m$ value are recommended as the basis for PG performance classification. The $m$ value reflects the sensitivity of stiffness to time and stress relaxation ability.
However, with a corresponding higher modulus or lower deflection, the greater the stress required to produce unit strain, indicating that the asphalt material is harder. Figure 8 plots the test results for base and modified asphalt by nano$\mathrm{TiO}_{2}$. As seen, the modulus of base and modified asphalt by nano- $\mathrm{TiO}_{2}$ decreases with time. However, the modulus of nano- $\mathrm{TiO}_{2}$-modified asphalt is larger by comparison and not more than $300 \mathrm{MPa}$, which meets the specification requirements. In Figure 8(b), the $m$ value of base asphalt and nano- $\mathrm{TiO}_{2}$-modified asphalt becomes larger as time goes on. The $m$ value at $60 \mathrm{~s}$ of nano- $\mathrm{TiO}_{2}$-modified asphalt is smaller, and the $m$ value is larger than or equal to 0.3 , meeting the specification requirements. Compared with base asphalt, nano- $\mathrm{TiO}_{2}$-modified asphalt has a larger modulus as well as a smaller $m$ value, representing that the anticrack of asphalt containing nano- $\mathrm{TiO}_{2}$ has been reduced slightly, but it can also meet the Superpave specification requirements, that is, the $m$ value is not less than 0.3 .

\subsection{Analysis of Pavement Performances and Viscoelastic Properties of the Asphalt Mixture}

3.2.1. Pavement Performances Analysis. Figure 9 summarizes the pavement performances of the asphalt mixture, DS, $\varepsilon_{B}, S_{B}$, and TSR. From Figure 9, it is observed that nano- $\mathrm{TiO}_{2}$ asphalt mixture has higher DS, which shows that the addition of nano- $\mathrm{TiO}_{2}$ would enhance antirutting ability. Nano- $\mathrm{TiO}_{2}$ can absorb the light components, then affecting the temperature sensitivity of modified asphalt. Nano- $\mathrm{TiO}_{2}$ have a certain surface activity, thereby enhancing antirutting of the modified asphalt mixture. 


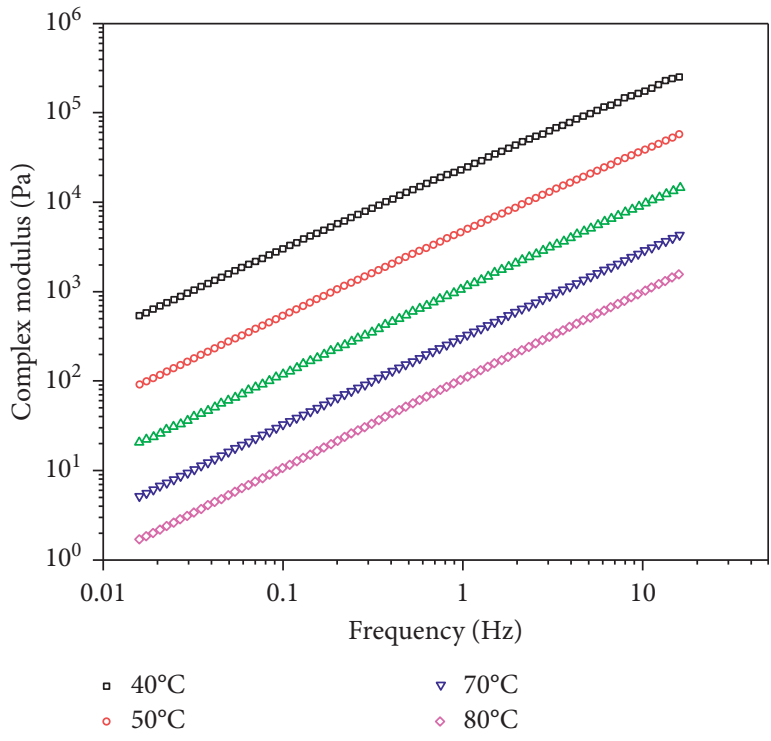

(a)

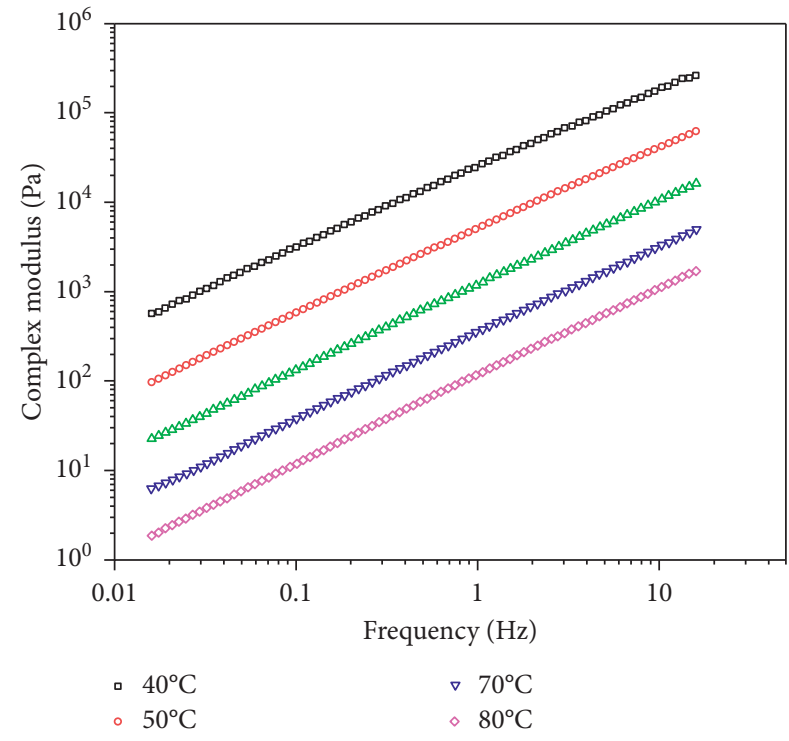

(b)

FiguRE 7: $G *$ results versus frequencies and temperatures of asphalt with and without nano- $\mathrm{TiO}_{2}$. (a) Base asphalt. (b) $\mathrm{Nano}^{-\mathrm{TiO}} \mathrm{O}_{2}$-modified asphalt.

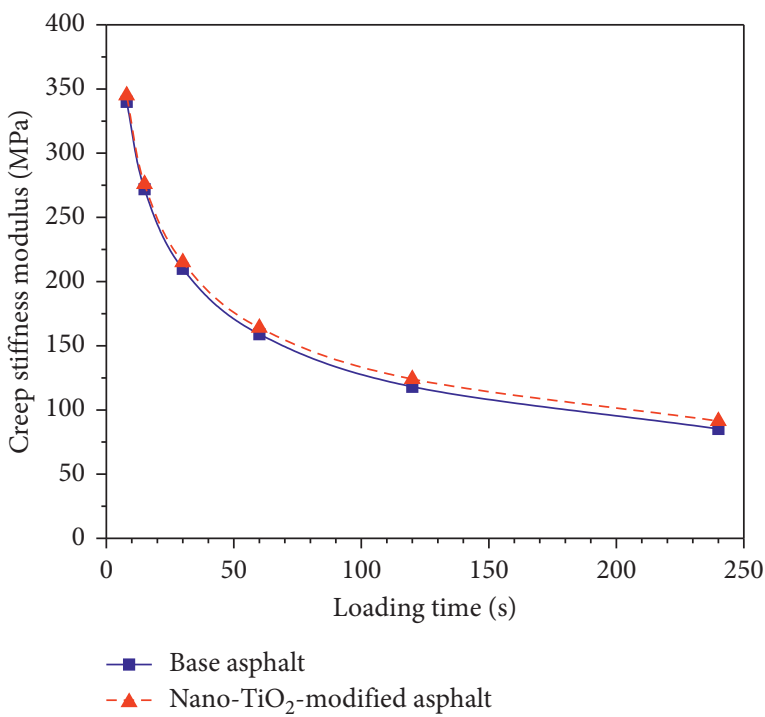

(a)

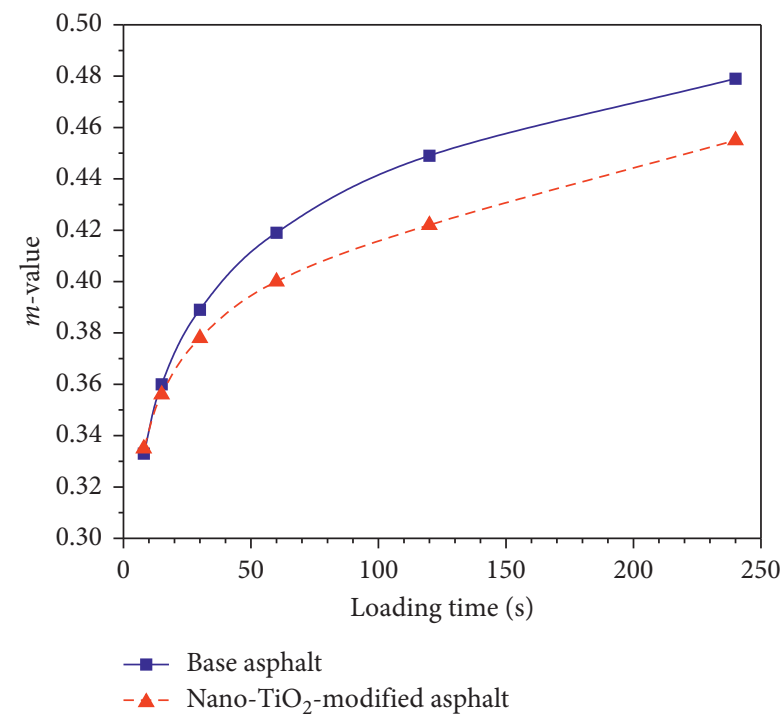

(b)

Figure 8: BBR comparison. (a) Modulus. (b) $m$ value.

Besides, the nano- $\mathrm{TiO}_{2}$ mixture possesses higher $\varepsilon_{B}$ and lower $S_{B}$. It could be considered that adding nano- $\mathrm{TiO}_{2}$ can improve $\varepsilon_{B}$ value and then reduce corresponding flexuraltensile stiffness modulus $\left(S_{B}\right)$. Thus, the nano- $\mathrm{TiO}_{2}$-modified mixture has a better anticracking ability at low temperature.

From the perspective of moisture stability, the nano$\mathrm{TiO}_{2}$ mixture possesses large TSR, which conforms to JTG F40-2004. This is because nano- $\mathrm{TiO}_{2}$ has a larger specific surface area, and it can improve the structural asphalt content, thereby improving the moisture stability of the modified mixture.

3.2.2. Static Creep Test Analysis. Generally, the viscous and elastic elements are generally combined in series or in parallel to represent the viscoelastic mechanical performances of asphalt mixtures, and the Burgers' model as well as its modified model are widely used and have good 


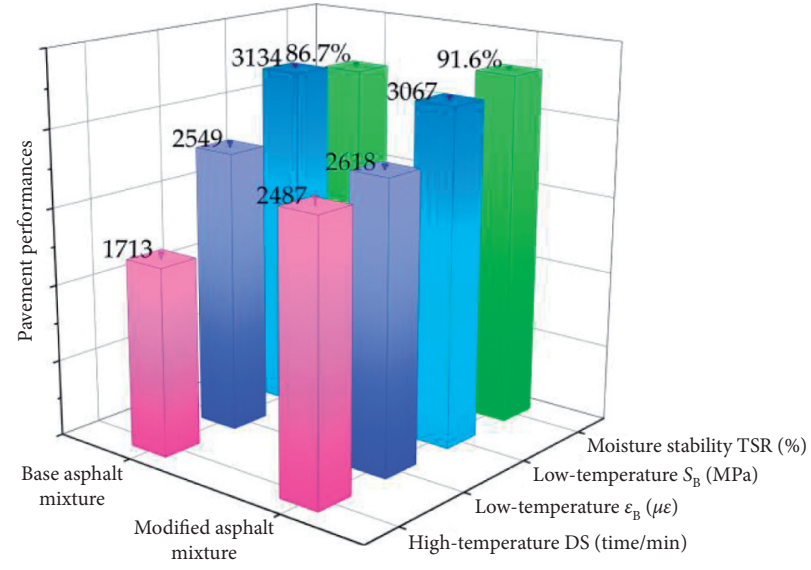

FIGURE 9: Pavement performances' comparison results.
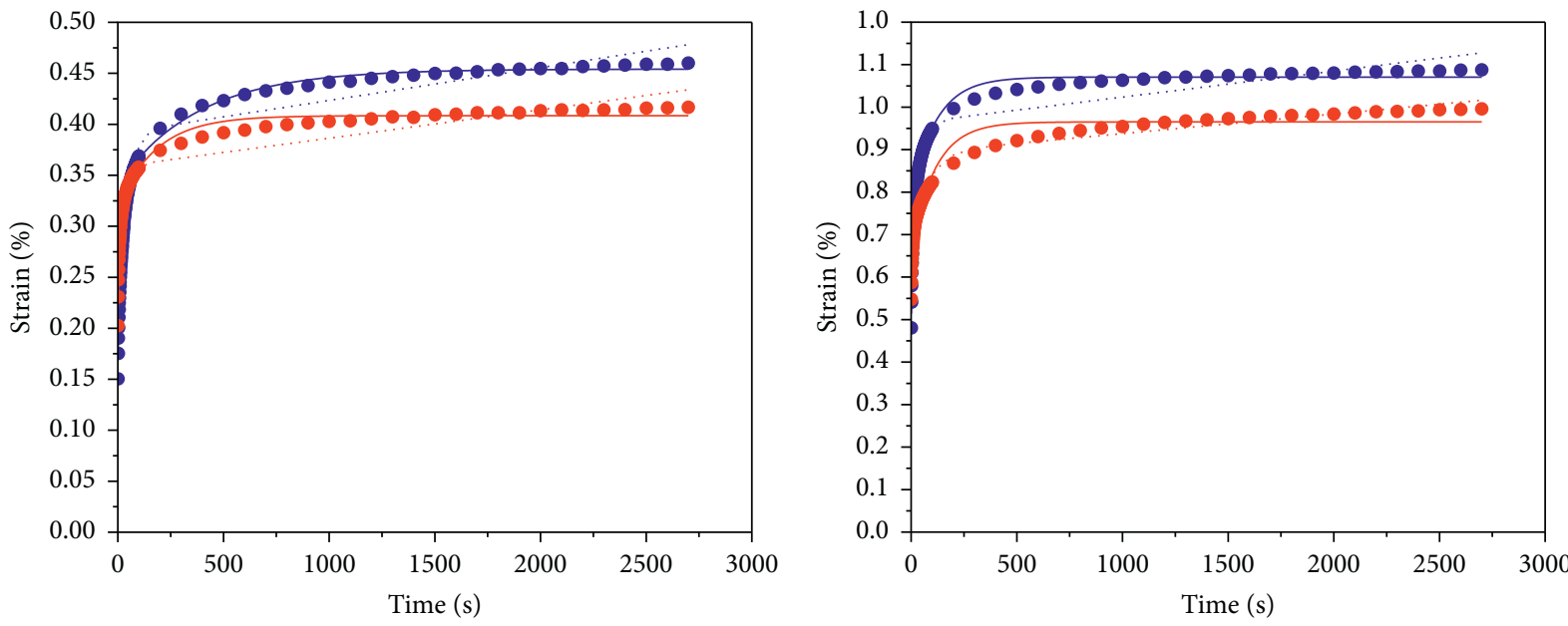

\begin{tabular}{|c|c|}
\hline $\begin{array}{l}\text { Base asphalt } \\
\text { mixture: }\end{array}$ & $\begin{array}{l}\mathrm{Nano}-\mathrm{TiO}_{2} \text {-modified } \\
\text { asphalt mixture: }\end{array}$ \\
\hline - Data & - Data \\
\hline Burgers model & .... Burgers model \\
\hline $\begin{array}{l}\text { Modified burgers } \\
\text { model }\end{array}$ & $\begin{array}{l}\text { Modified burgers } \\
\text { model }\end{array}$ \\
\hline
\end{tabular}

(a)

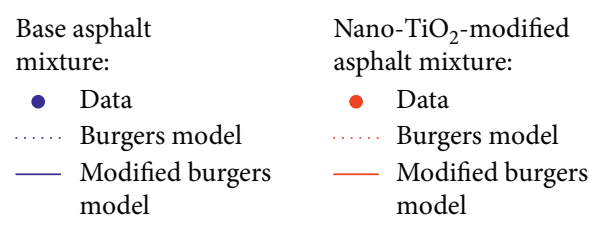

(b)

Figure 10: Comparative results of the Burgers' model and modified Burgers' model for asphalt mixtures versus time. (a) $20^{\circ} \mathrm{C}$. (b) $50^{\circ} \mathrm{C}$.

application effects $[53,54]$. The creep functions of these two models are given as follows:

$$
\begin{gathered}
\varepsilon(t)=\sigma_{0}\left[\frac{1}{E_{1}}+\frac{t}{\eta_{1}}+\frac{1}{E_{2}}\left(1-e^{\left(-E_{2} t / \eta_{2}\right)}\right)\right], \\
\text { for the Burgers' model, } \\
\varepsilon(t)=\sigma_{0}\left[\frac{1}{E_{1}}+\frac{\left(1-e^{-B t}\right)}{A B}+\frac{1}{E_{2}}\left(1-e^{\left(-E_{2} t / \eta_{2}\right)}\right)\right], \\
\text { for the modified Burgers' model. }
\end{gathered}
$$

The uniaxial static compression creep tests at $20^{\circ} \mathrm{C}$ and $50^{\circ} \mathrm{C}$ were conducted on base and modified asphalt by nano-
$\mathrm{TiO}_{2}$. Figure 10 illustrates the creep deformation results versus time. Both asphalt mixtures have similar creep deformation curves. At the loading stage, the creep deformation includes instant and delayed elastic as well as viscous flow deformations. Although incorporating nano- $\mathrm{TiO}_{2}$ will not change the creep deformation law of the asphalt mixture, nano- $\mathrm{TiO}_{2}$ could affect the creep deformation rate, cumulative deformation, and residual permanent deformation.

Figure 10 also plots the fitting curves of creep deformation for the base original asphalt mixture as well as the nano- $\mathrm{TiO}_{2}$ mixture. As seen, the modified Burgers' model is closer to actual measured creep deformation data, and the fitting accuracy is higher. The modified Burgers' model could consider the consolidation effect of the asphalt mixture, that is, the creep growth rate of the asphalt mixture gradually 


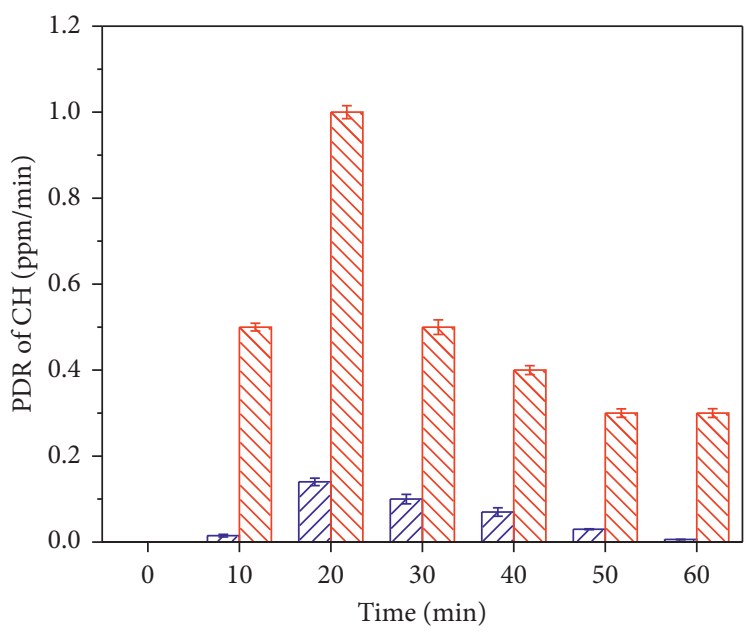

VIII Base asphalt mixture

MV Nano- $\mathrm{TiO}_{2}$-modified asphalt mixture

(a)

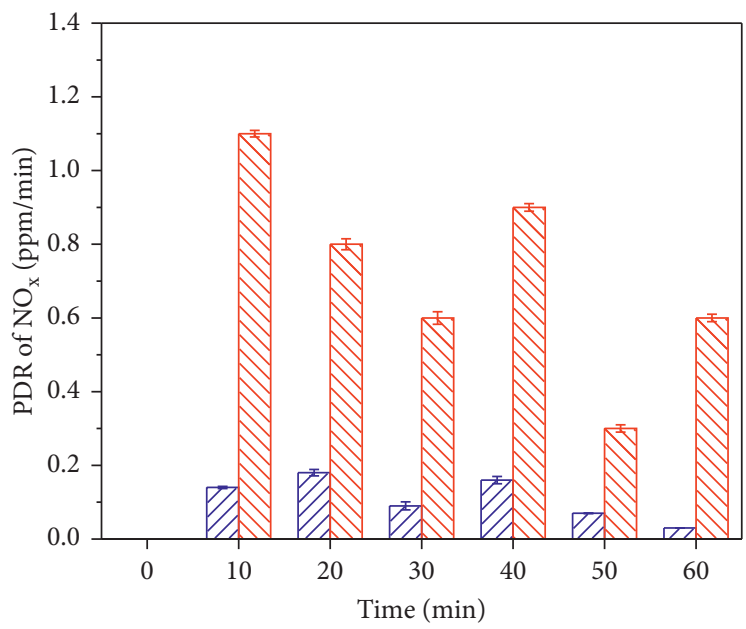

VIII Base asphalt mixture

MIV Nano- $\mathrm{TiO}_{2}$-modified asphalt mixture

(c)

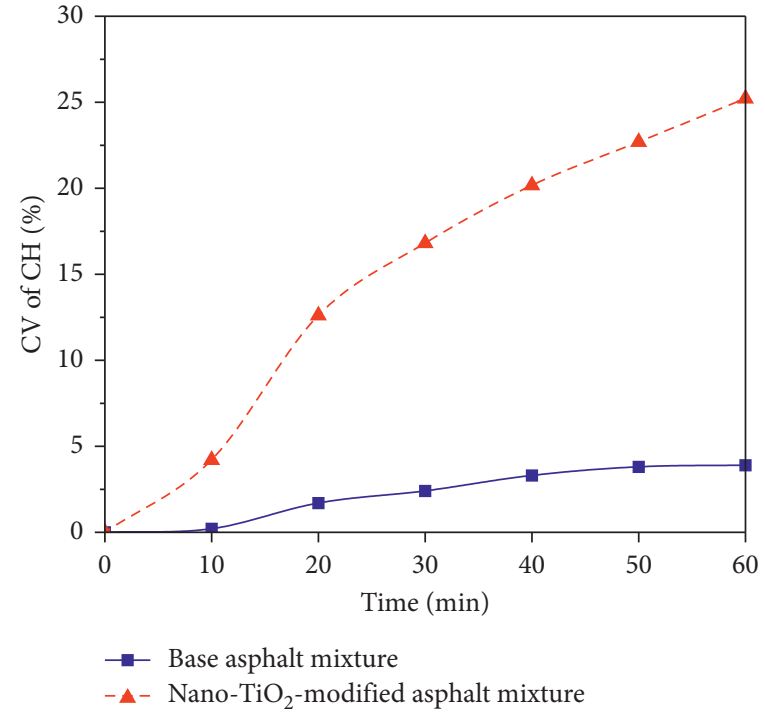

(b)

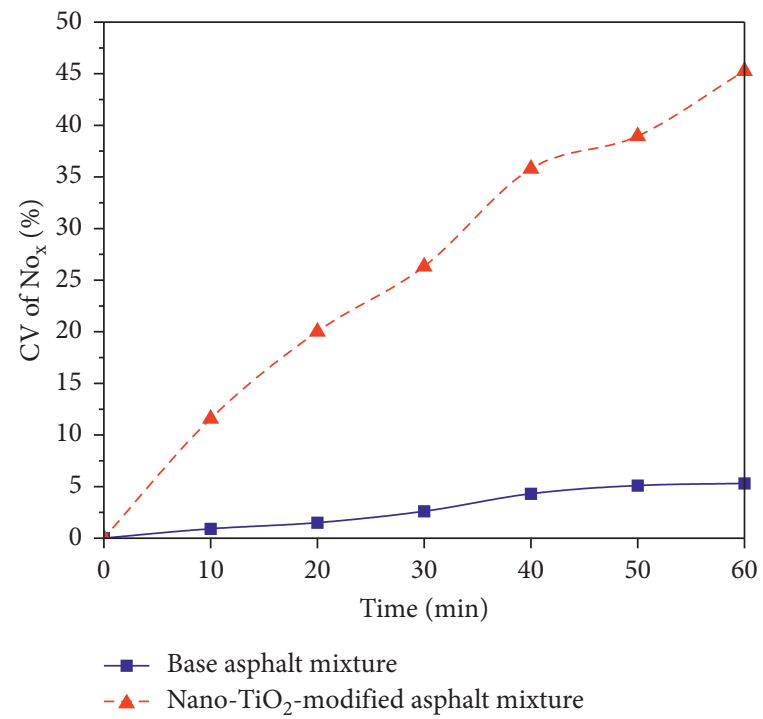

(d)

Figure 11: Photocatalytic degradation test results of automobile exhaust for asphalt mixtures with and without nano-TiO ${ }_{2}$. (a) $\mathrm{PDR}$ of $\mathrm{CH}_{\text {. }}$ (b) $\mathrm{CV}$ of $\mathrm{CH}$. (c) PDR of $\mathrm{NO}_{\mathrm{x} .}$. (d) $\mathrm{CV}$ of $\mathrm{NO}_{\mathrm{x}}$.

decreases in the actual creep process. However, the Burgers' model has good fitting results at the early stage of creep, but the creep deformation is gradually different from the actual deformation after the creep migration period. Therefore, the Burgers' model is more ideal, and the modified Burgers' model is closer to reality.

3.3. Analysis of the Photocatalytic Degradation Test of Automobile Exhaust. The photocatalytic degradation test was carried out for the asphalt mixture with and without $\mathrm{TiO}_{2}$ nanoparticles to monitor $\mathrm{CH}$ and $\mathrm{NO}_{\mathrm{x}}$ contents using the automobile exhaust gas analyzer. The initial concentrations of $\mathrm{CH}$ for the base original asphalt mixture as well as the nano- $\mathrm{TiO}_{2}$-modified asphalt mixture are $115 \mathrm{ppm}$ and
$119 \mathrm{ppm}$, respectively. The initial concentrations of $\mathrm{NO}_{\mathrm{x}}$ for the base original asphalt mixture as well as the nano$\mathrm{TiO}_{2}$-modified asphalt mixture are $112 \mathrm{ppm}$ and $95 \mathrm{ppm}$, respectively. Figures 11 (a) and 11(b) present the PDR and $\mathrm{CV}$ of $\mathrm{CH}$ for the base original asphalt mixture as well as the nano- $\mathrm{TiO}_{2}$-modified asphalt mixture. It is observed intuitively in Figure 11(a) that the PDR value of $\mathrm{CH}$ for both asphalt mixtures increase first and then decrease with time. In Figure 11(b), CH is continuously decreasing with time, which shows that the photocatalytic degradation rate of nano- $\mathrm{TiO}_{2}$ for $\mathrm{CH}$ in mixtures will gradually decrease with the reaction time. When the reaction time is about $20 \mathrm{~min}$, the PDR of nano- $\mathrm{TiO}_{2}$ for $\mathrm{CH}$ reaches the maximum, and the PDR value is about $1.0 \mathrm{ppm} / \mathrm{min}$. 
Figures $11(\mathrm{c})$ and $11(\mathrm{~d})$ present the PDR and CV of $\mathrm{NO}_{\mathrm{x}}$ for the base original asphalt mixture and nano- $\mathrm{TiO}_{2}$-modified mixture. From Figure 11(c), the photocatalytic degradation rate of nano- $\mathrm{TiO}_{2}$ for $\mathrm{NO}_{\mathrm{x}}$ has certain fluctuation and generally shows a slight downward trend with the reaction time. In Figure 11(d), it can be seen that the concentration of $\mathrm{NO}_{\mathrm{x}}$ is continuously decreasing with the reaction time, which shows that the PDR of nano- $\mathrm{TiO}_{2}$ for $\mathrm{NO}_{\mathrm{x}}$ in mixtures only decreases slightly with the reaction time.

The nano- $\mathrm{TiO}_{2}$-modified asphalt mixture has a very positive influence for purification of $\mathrm{CH}$ and $\mathrm{NO}_{\mathrm{x}}$. Due to the PDR above $0.4 \mathrm{ppm} / \mathrm{min}$, purification of $\mathrm{CH}$ by the modified asphalt mixture can be considered to occur mainly within 40 minutes during the reaction time, and the photocatalytic degradation efficiency is relatively high. While, the photocatalytic degradation of $\mathrm{NO}_{\mathrm{x}}$ by the nano- $\mathrm{TiO}_{2}$-modified asphalt mixture has a good degradation efficiency within 1 hour of the reaction time, although the degradation rate fluctuates. Theoretically, the PDR and CV of the base asphalt mixture will not change at all. However, the asphalt mixture is a kind of porous structure material, which may have a certain adsorption on $\mathrm{CH}$ and $\mathrm{NO}_{\mathrm{x}}$, resulting in its change. In general, adding nano- $\mathrm{TiO}_{2}$ can greatly improve the photocatalytic degradation treatment of automobile exhaust from asphalt mixtures. Meanwhile, the photocatalytic degradation effect of nano- $\mathrm{TiO}_{2}$-modified mixtures on $\mathrm{NO}_{\mathrm{x}}$ is significantly better than that of $\mathrm{CH}$.

\section{Conclusions}

In this work, nanomaterial (nano- $\mathrm{TiO}_{2}$ ) was used for asphalt, and then, nano- $\mathrm{TiO}_{2}$-modified asphalt was also added into the asphalt mixture. In addition, the conventional and rheological indicators of base and nano- $\mathrm{TiO}_{2}$-modified asphalt, as well as pavement performances and photocatalytic degradation of automobile exhaust of base and nano- $\mathrm{TiO}_{2}$-modified asphalt mixtures have been tested and analyzed. The following conclusions are drawn:

(1) $\mathrm{Nano}-\mathrm{TiO}_{2}$ can enhance the mechanical performances of asphalt. According to penetration and softening point tests, adding nano- $\mathrm{TiO}_{2}$ was beneficial to increase the viscosity and reduce the temperature sensitivity, which would enhance its high-temperature stabilization capability of asphalt.

(2) Rheological properties of asphalt can be improved by $\mathrm{TiO}_{2}$ nanoparticles significantly. Compared to base asphalt, nano- $\mathrm{TiO}_{2}$-modified asphalt has higher $G^{*}$ and lower $\delta$. Addition of nano- $-\mathrm{TiO}_{2}$ was beneficial to enhance the capacity of high-temperature antirutting of asphalt due to its larger rutting factor. The growth rate of the rutting factor for nano- $\mathrm{TiO}_{2}$-modified asphalt changes from $5 \%$ to $13 \%$ when the temperature range is $40^{\circ} \mathrm{C} \sim 80^{\circ} \mathrm{C}$.

(3) Due to the larger creep stiffness modulus (not more than $300 \mathrm{MPa}$ ) and smaller $m$ value (not less than 0.3 ), the low-temperature anticracking property of nano$\mathrm{TiO}_{2}$-modified asphalt is weaker. According to ductility results at $10^{\circ} \mathrm{C}$ and $m$ values of the BBR test, the low-temperature performance of nano- $\mathrm{TiO}_{2}$-asphalt could also comply with the Superpave specification.

(4) According to the analysis of pavement performances, adding nano- $\mathrm{TiO}_{2}$ can effectively enhance the antirutting and anticracking performances and water stabilization. Besides, the cumulative strain of asphalt mixtures can be accurately characterized by the modified Burgers' model.

(5) The nano- $\mathrm{TiO}_{2}$-modified asphalt mixture has a positive influence on the photocatalytic degradation of $\mathrm{CH}$ and $\mathrm{NO}_{\mathrm{x}}$, which could provide a reference for the treatment of automobile exhaust. Meanwhile, the photocatalytic degradation effect of nano- $\mathrm{TiO}_{2}$-modified asphalt mixtures on $\mathrm{NO}_{\mathrm{x}}$ is significantly better than that of $\mathrm{CH}$. The photocatalytic degradation of $\mathrm{CH}$ and $\mathrm{NO}_{\mathrm{x}}$ by the nano- $\mathrm{TiO}_{2}$-modified asphalt mixture can be considered to occur mainly within 40 minutes and 1 hour, respectively, during the reaction time.

\section{Data Availability}

The data used to support the findings of this study are available from the corresponding author upon request.

\section{Conflicts of Interest}

The authors declare that they have no conflicts of interest.

\section{Acknowledgments}

This work was funded by the Nanning Excellent Young Scientist Program (Grant no. RC20180108), Nanning Excellent Young Scientist Program and Guangxi Beibu Gulf Economic Zone Major Talent Program (Grant no. RC20190206), Science and Technology Base and Talent Special Project of Guangxi Province (Grant no. AD19245152), "Yongjiang Plan" of Nanning Leading Talents in Innovation and Entrepreneurship (Grant no. 2018-01-04), Scientific and Technological Project of Science and Technology Department of Jilin Province (Grant no. 20190303052SF), and the Innovation Special Project of Zhongshan Science and Technology Bureau (Grant no. 2019AG001).

\section{References}

[1] S. Mondal and K. P. Biligiri, "Crumb rubber and silica fume inclusions in pervious concrete pavement systems: evaluation of hydrological, functional, and structural properties," Journal of Testing and Evaluation, vol. 46, no. 3, pp. 892-905, 2018.

[2] Y. Gao, B. He, M. Xiao, Z. Fang, and K. Dai, "Study on properties and mechanisms of luminescent cement-based pavement materials with super-hydrophobic function," Construction and Building Materials, vol. 165, pp. 548-559, 2018.

[3] F. L. Tang, T. Ma, and Y. S. Guan, "Parametric modeling and structure verification of asphalt pavement based on bimabaqus," Automation in Construction, vol. 111, 2020. 
[4] F. L. Tang, T. Ma, and J. H. Zhang, "Integrating three-dimensional road design and pavement structure analysis based on bim," Automation in Construction, vol. 113, 2020.

[5] Q. Guo, L. Li, Y. Cheng, Y. Jiao, and C. Xu, "Laboratory evaluation on performance of diatomite and glass fiber compound modified asphalt mixture," Materials \& Design (1980-2015), vol. 66, pp. 51-59, 2015.

[6] Q. L. Guo, H. Y. Wang, and Y. Gao, "Investigation of the low-temperature properties and cracking resistance of fiber-reinforced asphalt concrete using the dic technique," Engineering Fracture Mechanics, vol. 229, 2020.

[7] M. Guo, M. C. Liang, and Y. B. Jiao, "A review of phase change materials in asphalt binder and asphalt mixture," Construction and Building Materials, vol. 258, 2020.

[8] M. Guo, H. Q. Liu, and Y. B. Jiao, "Effect of wma-rap technology on pavement performance of asphalt mixture: a state-of-the-art review," Journal of Cleaner Production, vol. 266, 2020.

[9] H. B. Liu, G. B. Luo, and X. Q. Wang, "Laboratory evaluation of the pavement performance of a rubber-modified asphalt mixture," Emerging Materials Research, vol. 9, no. 1, pp. 99-103, 2020.

[10] Z. B. Ren, Y. Q. Zhu, and Q. Wu, "Enhanced storage stability of different polymer modified asphalt binders through nanomontmorillonite modification," Nanomaterials, vol. 10, no. 4, 2020.

[11] M. L. Zheng, Y. J. Tian, and L. T. He, "Analysis on environmental thermal effect of functionally graded nanocomposite heat reflective coatings for asphalt pavement," Coatings, vol. 9, no. 3, 2019.

[12] G. Tan, Z. Zhu, and W. Wang, "Flexural ductility and crackcontrolling capacity of polypropylene fiber reinforced ecc thin sheet with waste superfine river sand based on acoustic emission analysis," Construction and Building Materials, vol. 277, 2021.

[13] H. N. Yu, W. Dai, and G. P. Qian, "The $\mathrm{NO}_{\mathrm{x}}$ degradation performance of nano- $\mathrm{TiO}_{2}$ coating for asphalt pavement," Nanomaterials, vol. 10, no. 5, 2020.

[14] T. Chen, Y. C. Luan, and T. Ma, "Mechanical and microstructural characteristics of different interfaces in cold recycled mixture containing cement and asphalt emulsion," Journal of Cleaner Production, vol. 258, 2020.

[15] J. P. Bilodeau, J. Y. Yi, and P. M. Thiam, "Surface deflection analysis of flexible pavement with respect to frost penetration," Journal of Cold Regions Engineering, vol. 33, no. 4, 2019.

[16] J. Q. Zhu, T. Ma, and J. W. Fan, "Experimental study of high modulus asphalt mixture containing reclaimed asphalt pavement," Journal of Cleaner Production, vol. 263, 2020.

[17] Q. L. Guo, Q. Liu, and P. Zhang, “Temperature and pressure dependent behaviors of moisture diffusion in dense asphalt mixture," Construction and Building Materials, vol. 246, 2020.

[18] Q. Guo, G. Li, Y. Gao et al., "Experimental investigation on bonding property of asphalt-aggregate interface under the actions of salt immersion and freeze-thaw cycles," Construction and Building Materials, vol. 206, pp. 590-599, 2019.

[19] Y. B. Jiao, L. D. Zhang, and Q. L. Guo, "Acoustic emissionbased reinforcement evaluation of basalt and steel fibers on low-temperature fracture resistance of asphalt concrete," Journal of Materials in Civil Engineering, vol. 32, no. 5, 2020.

[20] Y. B. Jiao, S. Q. Liu, and L. X. Fu, "Fracture monitoring of sbs and crumb rubber modified porous asphalt mixtures under compression and splitting testing using acoustic emission technique," Journal of Materials in Civil Engineering, vol. 31, no. $6,2019$.
[21] X. Y. Zhang, L. Xu, and J. X. Lv, "Investigation on the flexuraltensile rheological behavior and its influence factors of fiberreinforced asphalt mortar," Polymers, vol. 12, no. 9, 2020.

[22] C. Liang, X. Xu, and H. Chen, "Machine learning approach to develop a novel multi-objective optimization method for pavement material proportion," Applied Sciences, vol. 11, no. 2, 2021.

[23] X. H. Ding, T. Ma, and L. H. Gu, "Investigation of surface micro-crack growth behavior of asphalt mortar based on the designed innovative mesoscopic test," Materials \& Design, vol. $185,2020$.

[24] L. Garcia-Gil, R. Miró, and F. E. Pérez-Jiménez, "New approach to characterize cracking resistance of asphalt binders," Construction and Building Materials, vol. 166, pp. 50-58, 2018.

[25] X. Zhang, X. Gu, and J. Lv, "Effect of basalt fiber distribution on the flexural-tensile rheological performance of asphalt mortar," Construction and Building Materials, vol. 179, pp. 307-314, 2018.

[26] L. Brasileiro, F. Moreno-Navarro, and R. Tauste-Martinez, "Reclaimed polymers as asphalt binder modifiers for more sustainable roads: a review," Sustainability, vol. 11, no. 3, 2019.

[27] W. S. Wang, Y. C. Cheng, and H. P. Chen, "Study on the performances of waste crumb rubber modified asphalt mixture with eco-friendly diatomite and basalt fiber," Sustainability, vol. 11, no. 19, 2019.

[28] X. Zhang, X. Gu, J. Lv, Z. Zhu, and F. Ni, "Mechanism and behavior of fiber-reinforced asphalt mastic at high temperature," International Journal of Pavement Engineering, vol. 19, no. 5, pp. 407-415, 2018.

[29] W. S. Wang, Y. C. Cheng, and G. J. Tan, “Design optimization of sbs-modified asphalt mixture reinforced with eco-friendly basalt fiber based on response surface methodology," Materials, vol. 11, no. 8, 2018.

[30] S. G. Jahromi and A. Khodaii, "Effects of nanoclay on rheological properties of bitumen binder," Construction and Building Materials, vol. 23, no. 8, pp. 2894-2904, 2009.

[31] M. Abdelrahman, D. R. Katti, and A. Ghavibazoo, "Engineering physical properties of asphalt binders through nanoclay-asphalt interactions," Journal of Materials in Civil Engineering, vol. 26, no. 12, 2014.

[32] Z. You, J. Mills-Beale, J. M. Foley et al., "Nanoclay-modified asphalt materials: preparation and characterization," Construction and Building Materials, vol. 25, no. 2, pp. 1072-1078, 2011.

[33] M. J. Khattak, A. Khattab, H. R. Rizvi, and P. Zhang, "The impact of carbon nano-fiber modification on asphalt binder rheology," Construction and Building Materials, vol. 30, pp. 257-264, 2012.

[34] I. R. Segundo, C. Ferreira, and E. F. Freitas, “Assessment of photocatalytic, superhydrophobic and self-cleaning properties on hot mix asphalts coated with $\mathrm{TiO}_{2}$ and/or ZNO aqueous solutions," Construction and Building Materials, vol. 166, pp. 500-509, 2018.

[35] Y. Shu, J. Ji, Y. Xu et al., "Promotional role of mn doping on catalytic oxidation of vocs over mesoporous $\mathrm{TiO}_{2}$ under vacuum ultraviolet (vuv) irradiation," Applied Catalysis B: Environmental, vol. 220, pp. 78-87, 2018.

[36] M. M. Hassan, H. Dylla, S. Asadi, L. N. Mohammad, and S. Cooper, "Laboratory evaluation of environmental performance of photocatalytic titanium dioxide warm-mix asphalt pavements," Journal of Materials in Civil Engineering, vol. 24, no. 5, pp. 599-605, 2012.

[37] J. V. S. de Melo and G. Trichês, "Evaluation of the influence of environmental conditions on the efficiency of photocatalytic 
coatings in the degradation of nitrogen oxides (NOx)," Building and Environment, vol. 49, pp. 117-123, 2012.

[38] R. Ahmad, Z. Ahmad, A. U. Khan, N. R. Mastoi, M. Aslam, and J. Kim, "Photocatalytic systems as an advanced environmental remediation: recent developments, limitations and new avenues for applications," Journal of Environmental Chemical Engineering, vol. 4, no. 4, pp. 4143-4164, 2016.

[39] I. Kitsou, P. Panagopoulos, T. Maggos, and A. Tsetsekou, "ZNO-coated $\mathrm{SiO}_{2}$ nanocatalyst preparation and its photocatalytic activity over nitric oxides as an alternative material to pure ZNO," Applied Surface Science, vol. 473, pp. 40-48, 2019.

[40] A. A. Nada, W. M. A. El Rouby, and M. F. Bekheet, "Highly textured boron/nitrogen co-doped $\mathrm{TiO}_{2}$ with honeycomb structure showing enhanced visible-light photoelectrocatalytic activity," Applied Surface Science, vol. 505, 2020.

[41] G. B. Luo, H. B. Liu, and W. J. Li, "Automobile exhaust removal performance of pervious concrete with nano $\mathrm{TiO}_{2}$ under photocatalysis," Nanomaterials, vol. 10, no. 10, 2020.

[42] M. Chen and Y. Liu, "NOx removal from vehicle emissions by functionality surface of asphalt road," Journal of Hazardous Materials, vol. 174, no. 1-3, pp. 375-379, 2010.

[43] K. Hashimoto, H. Irie, and A. Fujishima, " $\mathrm{TiO}_{2}$ photocatalysis: a historical overview and future prospects," Japanese Journal of Applied Physics, vol. 44, no. 12, pp. 8269-8285, 2005.

[44] V. Loftness, B. Hakkinen, O. Adan, and A. Nevalainen, "Elements that contribute to healthy building design," Environmental Health Perspectives, vol. 115, no. 6, pp. 965-970, 2007.

[45] J. Jin, T. Xiao, Y. Tan et al., "Effects of TiO2 pillared montmorillonite nanocomposites on the properties of asphalt with exhaust catalytic capacity," Journal of Cleaner Production, vol. 205, pp. 339-349, 2018.

[46] G. Qian, H. Yu, X. Gong, and L. Zhao, "Impact of Nano-TiO2 on the NO2 degradation and rheological performance of asphalt pavement," Construction and Building Materials, vol. 218, pp. 53-63, 2019.

[47] Y. Gong, H. Bi, Z. Tian, and G. Tan, "Pavement performance investigation of nano- $\mathrm{TiO} 2 / \mathrm{CaCO} 3$ and basalt fiber composite modified asphalt mixture under freeze-thaw cycles," Applied Sciences, vol. 8, no. 12, p. 2581, 2018.

[48] J. M. Yu, F. D. Chen, and W. Deng, "Design and performance of high-toughness ultra-thin friction course in South China," Construction and Building Materials, vol. 246, 2020.

[49] W. Wang, Y. Cheng, G. Tan, and C. Shi, "Pavement performance evaluation of asphalt mixtures containing oil shale waste," Road Materials and Pavement Design, vol. 21, no. 1, pp. 179-200, 2020.

[50] Y. C. Cheng, W. S. Wang, and G. J. Tan, “Assessing high- and low-temperature properties of asphalt pavements incorporating waste oil shale as an alternative material in Jilin province, China," Sustainability, vol. 10, no. 7, 2018.

[51] W. Wang, Y. Cheng, G. Tan, Z. Liu, and C. Shi, "Laboratory investigation on high- and low-temperature performances of asphalt mastics modified by waste oil shale ash," Journal of Material Cycles and Waste Management, vol. 20, no. 3, pp. 1710-1723, 2018.

[52] Y. Zhang, T. Ma, and M. Ling, "Predicting dynamic shear modulus of asphalt mastics using discretized-element simulation and reinforcement mechanisms," Journal of Materials in Civil Engineering, vol. 31, no. 8, 2019.

[53] W. S. Wang, G. J. Tan, and C. Y. Liang, "Study on viscoelastic properties of asphalt mixtures incorporating sbs polymer and basalt fiber under freeze-thaw cycles," Polymers, vol. 12, no. 8 , 2020.

[54] W. S. Wang, Y. C. Cheng, and P. L. Zhou, "Performance evaluation of styrene-butadiene-styrene-modified stone mastic asphalt with basalt fiber using different compaction methods," Polymers, vol. 11, no. 6, 2019.

[55] C. Wu, L. Li, and W. Wang, "Experimental characterization of viscoelastic behaviors of nano $\mathrm{TiO}_{2} / \mathrm{CaCO}_{3}$ modified asphalt and asphalt mixture," Nanomaterials (Basel), vol. 11, no. 1, 2021. 